\title{
Microbiome Studies in Non-human Primates
}

\author{
Jason M. Brenchley ${ }^{1} \cdot$ Alexandra M. Ortiz $^{1}$ \\ Accepted: 12 October 2021 / Published online: 4 November 2021 \\ This is a U.S. government work and not under copyright protection in the U.S.; foreign copyright protection may apply 2021
}

\begin{abstract}
Purpose of Review Observations of differing bacterial, intestinal microbiomes in people living with HIV have propelled interest in contributions of the microbiome to HIV disease. Non-human primate (NHP) models of HIV infection provide a controlled setting for assessing contributions of the microbiome by standardizing environmental confounders. We provide an overview of the findings of microbiome contributions to aspects of HIV disease derived from these animal models.

Recent Findings Observations of differing bacterial, intestinal microbiomes are inconsistently observed in the NHP model following SIV infection. Differences in lentiviral susceptibility and vaccine efficacy have been attributed to variations in the intestinal microbiome; however, by-and-large, these differences have not been experimentally assessed.

Summary Although compelling associations exist, clearly defined contributions of the microbiome to HIV and SIV disease are lacking. The empirical use of comprehensive multi-omics assessments and longitudinal and interventional study designs in NHP models is necessary to define this contribution more clearly.
\end{abstract}

Keywords HIV $\cdot$ SIV $\cdot$ Non-human primate $\cdot$ Microbiome $\cdot$ Dysbiosis

\section{Introduction}

The commensal microbiome plays an essential role in the development and maintenance of systemic health through antagonism of pathobionts and the production of metabolites which tune immunity and epithelial integrity $[1,2]$. In turn, perturbations of the commensal microbiome are associated with systemic shifts in immune homeostasis and contribute to disease susceptibility and outcome. Observations of differing bacterial, intestinal microbiomes in people living with HIV (PLWH) compared to population controls have led to extensive interest regarding the contribution of the microbiome to HIV disease, susceptibility, and vaccine responsiveness [3-14]. In PLWH, dysbiosis - an imbalance of the microbiome favoring an expansion of pathobionts relative to commensal species - correlates with viral load and markers of inflammation $[3,5,6]$. These observations are

This article is part of the Topical Collection on HIV Pathogenesis and Treatment

\section{Alexandra M. Ortiz}

1 Barrier Immunity Section, Laboratory of Viral Diseases, National Institutes of Allergy and Infectious Diseases (NIAID), National Institutes of Health (NIH), Bethesda, USA particularly intriguing given the documented contribution of microbial translocation to persistent inflammation in disease progression [15-17]. Indeed, dysbiotic taxa have been identified to preferentially translocate [18-20]. It remains unclear whether observations of intestinal dysbiosis are a cause or a consequence of the immunopathologies associated with HIV disease, or how confounding variables contribute.

Non-human primates (NHPs) share $\sim 90 \%$ sequence homology with humans and SIV-infection of Asian macaques with $\mathrm{SIV}_{\mathrm{mac}}$ isolates recapitulates key aspects of HIV-1 infection [21-23]. Macaques and humans too share several dominant, gastrointestinal bacterial taxa, though differing at the species level [24, 25]. Herein we review recent published data describing potential contributions of the microbiome to various aspects of SIV disease. These studies have provided new insights and highlight experimental considerations that can be taken moving forward.

\section{What's Dysbiosis Got to Do with It?}

The contribution of intestinal microbial dysbiosis to HIV disease progression has emerged as a highly contentious specialty in HIV research. Several publications have reported the presence of a definable dysbiosis in 
PLWH - an enrichment of Proteobacteria at the expense of Firmicutes (Gammaproteobacteria and Clostridia, in particular) and among Bacteroidetes, an increase in the Prevotella:Bacteroides ratio [3-6]. This dysbiosis has been shown to correlate with biomarkers of disease progression - including CD4 + T-cell depletion, microbial translocation, and inflammation - and to persist after initiation of antiretroviral therapy (ART) [3-6, 26-29]. These observations are not universal, however. Several publications have demonstrated that these microbial signatures are prevalent among HIV-uninfected men who have sex with men, and that failure to balance cohorts by sexual practice biases study outcomes [30-33]. Efforts to assess the presence of dysbiosis in the SIV NHP model have led to similarly conflicting results $[20,25,34-41,42 \bullet \bullet]$. As shown in Table 1, variations in anatomic sites sampled, study design, infection stage, NHP species, and viral clone may contribute to differing outcomes. Where the microbiome is concerned, crosssectional sampling can lead to drastically differing outcomes $[43,44 \bullet \bullet, 45]$. Importantly, whereas studies in PLWH where dysbiosis has been observed have identified sweeping and largely consistent changes in the microbiome, reported SIVassociated changes to the microbiome are disparate and limited and result in widely varying interpretations. For example, whereas Klase et al. observed temporal fluctuations in Proteobacteria and Lactobacillus and did not interpret this to reflect dysbiosis, Glavan et al. observed changes to 4 genera and interpreted this as dysbiosis [20,35]. Whereas dysbiosis itself may be ambiguous, it is clear that where taxonomic changes are observed, SIV infection does not recapitulate the changes in the intestinal microbiome reported in HIV studies. Data are still emerging regarding the potential of dysbiosis at non-intestinal sites [46-50].

Following the initiation of ART, studies agree that an altered intestinal microbiome in PLWH and SIV-infected macaques exists [4-6, 20, 26-29, 37, 39]. First described by Klase et al., ART initiation led to perturbations in bacterial phyla distribution, including a loss of Firmicutes - despite a specific increase of Lactobacillus - and an increase in Proteobacteria [20]. The ART-associated increase of Proteobacteria was further observed by Siddiqui et al. and the Lactobacillus increase by Blum et al. [37, 39]. It remains unclear whether these ART-induced changes represent a microbial disruption or a recalibration towards the preinfection microbiome. Whereas neither longitudinal study comprehensively compared the pre-infection versus posttherapy microbiome, Blum et al. reported a significant cross-sectional difference in measures of beta-diversity [20, 37, 39]. Supporting a novel ART-initiated disruption to the intestinal microbiome, we recently examined the influence of individual antiretrovirals on the healthy macaque intestinal microbiome. In Ortiz et al., we observed that shortterm administration (1-6 weeks) of antiretrovirals led to instability of the fecal microbiome - no prolonged changes were observed in individual taxa [51]. These findings are in contrast to pre-exposure prophylaxis microbiome studies in humans, where changes in individual taxa were reported [52-54]. Further research is needed to understand whether these observed post-therapeutic differences are an effect of treatment longevity, route or formulation, longitudinal versus cross-sectional sampling, or host species specificity.

Irrespective of whether lentiviral infections result in a taxa-specific dysbiosis or microbial instability, there remains a question of whether dysbiosis contributes to disease. Lentiviral infections induce massive immunological and physical upheaval, and it is conceivable that any effect dysbiosis may normally have on intestinal immunity is overshadowed by infection. To this end, we treated rhesus macaques with vancomycin both prior to and throughout SIV infection in order to assess whether experimental dysbiosis contributes to SIV disease progression [42••]. Vancomycin induces a specific dysbiosis, inhibiting the ability of Gram + taxa to expand, thereby permitting Gram- taxa to flourish [55]. In our macaques, vancomycin treatment led to an enrichment of intestinal Gammaproteobacteria at the expense of Clostridia, an increase in Prevotella:Bacteroides, a shift in the intestinal bacterial metagenome, and a decline in the integrity of the intestinal epithelium. Despite these, vancomycintreated animals did not exhibit a more rapid progression to AIDS. While humans and macaques are separate species, each harboring their own unique microbiome, the nearly parallel course of lentiviral disease progression in humans and macaques suggests that the microbiome in each species exerts a similar effect on disease outcome [24, 25]. While secondary bacterial infections - dysbioses per se - do complicate disease progression, antibiotic regimens to treat these infections are clinically indicated, with long-term use counter-indicated out of concern for the development of antibiotic resistance [56-58].

Clarity regarding the presence of intestinal bacterial dysbiosis and its contribution to progressive lentiviral disease progression has largely been mired by contextual ambiguity. Progressive HIV and SIV infections can be roughly divided into multiple stages: acquisition, acute and chronic infection, and AIDS. Perturbations in intestinal bacterial communities may exert an outsized influence on any one of these stages without uniformly contributing to disease progression. Sui et al. recently observed that cohorts of rhesus macaques obtained from different sources had significantly differing susceptibilities to rectal SHIV acquisition [44••]. Differences in susceptibility were attributed to significantly higher levels of target CD4 + T-cells and rectal inflammation which in turn, correlated with a an elevated intestinal Prevotella:Bacteroides ratio. Concerning established infection, Handley et al. observed that significant shifts in the bacterial microbiome were evident only in end-stage 
Table 1 Publications that have assessed the presence of intestinal bacterial dysbiosis in SIV-infected macaques

\begin{tabular}{|c|c|c|c|c|c|c|c|c|}
\hline Publication & Species & Source & Study design & Virus & $\begin{array}{l}\text { Infection } \\
\text { phase }\end{array}$ & $\alpha$-diversity & $\beta$-diversity & $\begin{array}{l}\text { Taxa observations as } \\
\text { compared to uninfected }\end{array}$ \\
\hline $\begin{array}{l}\text { Allers et al. } \\
\text { [34] }\end{array}$ & Macaca mulatta & $\begin{array}{l}\text { Colonic } \\
\text { mucosa }\end{array}$ & Longitudinal & SIVmac251 & Acute & $\begin{array}{l}\text { Significant } \\
\text { increase }\end{array}$ & N/A & $\begin{array}{l}\text { Bacteroidetes (Bacte- } \\
\text { roidia and Alistipes) } \\
\text { increased. Firmicutes } \\
\text { (Ruminococcaceae } \\
\text { and Eubacteriaceae) } \\
\text { increased }\end{array}$ \\
\hline $\begin{array}{l}\text { Glavan et al. } \\
\text { [35] }\end{array}$ & Macaca mulatta & $\begin{array}{l}\text { Jejunal } \\
\text { mucosa }\end{array}$ & $\begin{array}{l}\text { Cross-sec- } \\
\text { tional }\end{array}$ & SIVmac251 & Acute & N/A & N/A & $\begin{array}{l}\text { Proteobacteria (Actino- } \\
\text { bacillus) increased }\end{array}$ \\
\hline $\begin{array}{l}\text { Klase et al. } \\
{[20]}\end{array}$ & $\begin{array}{l}\text { Macaca nemis- } \\
\text { trina }\end{array}$ & Feces & Longitudinal & SIVmac239 & Acute & N/A & N/A & $\begin{array}{l}\text { Lactobacillus decreased, } \\
\text { Proteobacteria } \\
\text { increased }\end{array}$ \\
\hline $\begin{array}{l}\text { Handley } \\
\text { et al. [36] }\end{array}$ & Macaca mulatta & Feces & Longitudinal & SIVmac251 & Acute & Not significant & $\begin{array}{l}\text { Not signifi- } \\
\text { cant }\end{array}$ & $\begin{array}{l}\text { No significant differ- } \\
\text { ences observed }\end{array}$ \\
\hline $\begin{array}{l}\text { McKenna } \\
\text { et al. [25] }\end{array}$ & Macaca mulatta & Feces & Longitudinal & SIVmac251 & Acute & N/A & $\begin{array}{l}\text { Not signifi- } \\
\text { cant }\end{array}$ & Not reported \\
\hline $\begin{array}{l}\text { Siddiqui } \\
\text { et al. [37] }\end{array}$ & Macaca mulatta & Feces & $\begin{array}{l}\text { Cross-sec- } \\
\text { tional }\end{array}$ & SIVmac239 & Acute & $\begin{array}{c}\text { Significant } \\
\text { decrease }\end{array}$ & $\begin{array}{l}\text { Significant } \\
\text { difference }\end{array}$ & $\begin{array}{l}9 \text { (unidentified) OTUs } \\
\text { significantly differed }\end{array}$ \\
\hline $\begin{array}{l}\text { Vujkovic- } \\
\text { Cvijin et al. } \\
{[38]}\end{array}$ & Macaca mulatta & Feces & Longitudinal & SIVmac251 & Acute & $\begin{array}{c}\text { Significant } \\
\text { decrease }\end{array}$ & $\begin{array}{l}\text { Significant } \\
\text { difference }\end{array}$ & $\begin{array}{l}\text { Lactobacillus and Strep- } \\
\text { tococcus genera and } \\
\text { spp. decreased }\end{array}$ \\
\hline $\begin{array}{l}\text { Allers et al. } \\
\text { [34] }\end{array}$ & Macaca mulatta & $\begin{array}{l}\text { Colonic } \\
\text { mucosa }\end{array}$ & Longitudinal & SIVmac251 & Chronic & Not significant & N/A & $\begin{array}{l}\text { Bacteroidetes (Bacte- } \\
\text { roidia) increased }\end{array}$ \\
\hline $\begin{array}{l}\text { Klase et al. } \\
\text { [20] }\end{array}$ & Macaca mulatta & $\begin{array}{l}\text { Colonic } \\
\text { mucosa }\end{array}$ & Longitudinal & SIVmac239 & Chronic & N/A & N/A & $\begin{array}{l}\text { No significant differ- } \\
\text { ences observed }\end{array}$ \\
\hline $\begin{array}{l}\text { Glavan et al. } \\
\text { [35] }\end{array}$ & Macaca mulatta & $\begin{array}{l}\text { Jejunal } \\
\text { mucosa }\end{array}$ & $\begin{array}{l}\text { Cross-sec- } \\
\text { tional }\end{array}$ & SIVmac251 & Chronic & N/A & N/A & $\begin{array}{l}3 \text { genera differed includ- } \\
\text { ing an increase in Fir- } \\
\text { micutes Streptococcus } \\
\text { and Staphylococcus }\end{array}$ \\
\hline $\begin{array}{l}\text { Blum et al. } \\
\text { [39] }\end{array}$ & Macaca mulatta & Feces & $\begin{array}{l}\text { Cross-sec- } \\
\text { tional }\end{array}$ & SIVmac251 & Chronic & Not significant & $\begin{array}{l}\text { Significant } \\
\text { difference }\end{array}$ & $\begin{array}{l}8 \text { OTUs differed includ- } \\
\text { ing a decline of } 3 \\
\text { Prevotella copri }\end{array}$ \\
\hline $\begin{array}{l}\text { Klase et al. } \\
{[20]}\end{array}$ & $\begin{array}{l}\text { Macaca nemis- } \\
\quad \text { trina }\end{array}$ & Feces & Longitudinal & SIVmac239 & Chronic & N/A & N/A & $\begin{array}{l}\text { Lactobacillus decreased, } \\
\text { Proteobacteria } \\
\text { decreased }\end{array}$ \\
\hline $\begin{array}{l}\text { Handley } \\
\text { et al. [36] }\end{array}$ & Macaca mulatta & Feces & Longitudinal & SIVmac251 & Chronic & Not significant & $\begin{array}{l}\text { Not signifi- } \\
\text { cant }\end{array}$ & $\begin{array}{l}\text { No significant differ- } \\
\text { ences observed }\end{array}$ \\
\hline $\begin{array}{l}\text { Handley } \\
\text { et al. [40] }\end{array}$ & Macaca mulatta & Feces & $\begin{array}{l}\text { Cross-sec- } \\
\text { tional }\end{array}$ & SIVmac251 & Chronic & N/A & $\begin{array}{l}\text { Not signifi- } \\
\text { cant }\end{array}$ & $\begin{array}{l}\text { No significant differ- } \\
\text { ences observed }\end{array}$ \\
\hline $\begin{array}{l}\text { Klatt et al. } \\
\text { [41] }\end{array}$ & $\begin{array}{l}\text { Macaca nemis- } \\
\quad \text { trina }\end{array}$ & Feces & Longitudinal & SIVmac239 & Chronic & N/A & N/A & $\begin{array}{l}\text { No significant differ- } \\
\text { ences observed }\end{array}$ \\
\hline $\begin{array}{c}\text { Ortiz et al. } \\
{[42 \bullet \bullet]}\end{array}$ & Macaca mulatta & Feces & Longitudinal & SIVmac239 & Chronic & Not significant & $\begin{array}{l}\text { Not signifi- } \\
\text { cant }\end{array}$ & $\begin{array}{l}\text { No significant differ- } \\
\text { ences observed }\end{array}$ \\
\hline $\begin{array}{l}\text { Ortiz et al. } \\
{[42 \bullet \bullet]}\end{array}$ & Macaca mulatta & Feces & Longitudinal & SIVmac239 & AIDS & Not significant & $\begin{array}{l}\text { Not signifi- } \\
\text { cant }\end{array}$ & $\begin{array}{l}\text { No significant differ- } \\
\text { ences observed }\end{array}$ \\
\hline $\begin{array}{l}\text { Handley } \\
\text { et al. [36] }\end{array}$ & Macaca mulatta & Feces & Longitudinal & SIVmac251 & AIDS & Not significant & $\begin{array}{l}\text { Significant } \\
\text { difference }\end{array}$ & $\begin{array}{l}\text { Firmicutes (Ruminococ- } \\
\text { caceae and Clostridi- } \\
\text { ales) and Proteobacte- } \\
\text { ria (Moraxellaceae and } \\
\text { Enterobacteriaceae) } \\
\text { decreased }\end{array}$ \\
\hline
\end{tabular}

$N / A$, not assessed

animals, absent prior to AIDS progression [36]. Macaques that had progressed to AIDS displayed an enrichment of Enterobacteriaceae, Moraxellaceae, Ruminococacceae, and Clostridiales. A dysbiosis index in PLWH was similarly associated with nadir CD4 + T-cell count, suggesting dysbiosis is more prominent in individuals with advanced 
disease $[33,59]$. Importantly, studies in natural, non-progressing hosts of SIV infection have demonstrated microbiome instability in SIV-infected AGMs and chimpanzees as compared to uninfected counterparts, with significant perturbations evident only in animals displaying visible illness [60-62]. Collectively, these findings indicate that the presence of bacterial dysbiosis does not necessitate disease progression throughout acute or chronic infection though a causal relationship may emerge in late-stage disease.

Finally, a lack of cohesion regarding the identification of dysbiotic taxa may be associated with the use of phylogenetic determinations of dysbiosis. In humans, proteomic and metagenomic approaches have been used to concurrently identify bacterial taxa and bacterial functional capacity [29, 63]. The use of longitudinal, multi-omics approaches to bacterial identification may identify core dysbiotic signatures in SIV-infected macaques and in turn, networks of functionally related bacteria or low-abundance keystone taxa that are associated with different aspects of progressive disease [64, 65]. The use of empiric experimental methods will be necessary to determine the relevance of any identified changes.

\section{Vaccination and the Bugs Within}

Understanding the interaction between the microbiome and vaccine modalities may better inform the development and utilization of vaccines. Certain microbiome profiles may negatively impact immune responses to certain vaccine modalities, and the microbiome may influence optimal prime boost time windows. Moreover, modalities to alter the microbiome may enhance vaccine immune responses [66].

The microbiome has been shown to calibrate anti-HIV immunity in response to candidate HIV vaccine administration. In humans, acute HIV-1 antibody responses are characterized by non-neutralizing, anti-gp41 immunodominance, which was mirrored by vaccination with an HIV-1 envelope DNA/recombinant adenovirus virus type 5 (rAd5) strategy $[67,68]$. This gp41-skewed response has been attributed to the presence of intestinal B-cells - generated in response to bacterial RNA polymerase and pyruvate-flavodoxin oxidoreductase - that produce antibodies which cross-react with gp41 [68, 69]. In an effort to understand the nature and development of this gp41-immunodominance, Han et al. vaccinated rhesus macaques with the HVTN 505 DNA/rAd5 vaccine and observed that for both adults and neonates, a tier 2 (moderate neutralization activity) gp41 immunodominant response was generated post-vaccination [70]. Both human and macaque gp41-reactive antibodies (mAbs) were crossreactive against macaque fecal proteins, with a candidate gp41-reactive bacterial polymerase epitope present both before and after vaccination [68, 70]. Intriguingly, $40 \%$ each of tested gp41-reactive and gp120-reactive macaque mAbs bound macaque fecal proteins. As the gp120 response lags behind the gp41 response, it is unlikely that microbial proteins prime the gp120 response [67]. This study underscores the utility of the NHP model in identifying bacterial components responsible for the development of poly-reactive mAbs.

Alterations to immunity by disease, diet, or pharmaceuticals can reciprocally calibrate the microbiome, and vaccine administration is no exception. Several groups demonstrated that irrespective of vaccine modality or route of administration, SHIV vaccination induces significant shifts in the rectal microbiome. In Sui et al., the assessment of macaques receiving adjuvanted MVA-SIV revealed that low-dose rectal SHIV $\mathrm{SF}_{\mathrm{S} 162 \mathrm{P} 4}$ acquisition was not associated with anti-Env immunity [71]. Indeed, no to very low levels of SHIV-specific antibodies were found and neither antiEnv nor anti-Gag CD4 + and CD8 + T-cell responses correlated with a delay of viral acquisition. Instead, bacterial richness and beta-diversity were found to differ significantly between the vaccinated and naive group after vaccination which negatively correlated with viral acquisition. Musich et al. similarly observed significant differences in the rectal microbiome following vaccination and, intriguingly, observed that empty vector control animals displayed shifts in the rectal microbiome indistinguishable from vaccinated animals [72]. Here, both vaccinated and control animals exhibited significant shifts in measures of beta diversity, a loss of Bacteroidetes, and an increase in Proteobacteria. With both vaccinated and control animals exhibiting comparable infection risk, these shifts in the microbiome were not associated with protection from low-dose, rectal, SIV $_{\text {mac251 }}$ challenge. However, frequencies of specific taxa correlated with significantly reduced peak viral load in vaccinated animals and Env-specific rectal IgA, which in turn correlated with acquisition risk.

A comparison of the female versus male rectal microbiome in Musich et al. revealed that females showed a greater magnitude of responsiveness following immunization and revealed sex-specific relationships between individual taxa and peak viral load and with biomarkers of protective efficacy [72]. In females alone, Elizaldi et al. observed that shifts in the rectal microbiome were not accompanied by significant or prolonged shifts in the vaginal microbiome following vaccination with plasmid-encoded SHIV Env/gp140 protein [73]. Here too, vaccination led to a loss of rectal Bacteroidetes, including Prevotella, and an increase in the Fimicute:Bacteroidetes ratio. Although vaccine efficacy was not assessed in this particular study, the pre-vaccination frequency of Prevotella predicted post-boost rectal HIV-1 Env IgG concentrations. 
Although these particular studies highlight the importance of understanding the interplay between the microbiome and vaccine development, several outstanding questions remain. Vaccine components are unlikely to directly interact with the intestinal microbiome in cases of non-mucosal administration; however, they may influence the microbiome in mucosal vaccine delivery. Untangling cause and effect may be possible with very detailed time course experiments. Also, particular vaccine components may influence the composition of the microbiome. The studies detailed above used differing vectors, modalities, and adjuvants and all induced shifts in the microbiome, with Musich et al. reporting that alum-adjuvanted control macaques too had demonstrable shifts in the rectal microbiome [72]. A thorough assessment of the effects of individual vaccine components on the microbiome is warranted. Moreover, timing of prime/ boost vaccine strategies may influence the microbiome. The studies detailed here spanned 0-38 weeks but it is unclear if observed microbiome shifts are permanent and whether longevity of perturbation might correlate with vaccine efficacy. Furthermore, as the composition of the microbiome impacts systemic health, it will be of interest to determine whether - weighed against the risk of contracting HIV vaccine-induced shifts in the microbiome influence health and responsiveness to heterologous infections. Lastly, can one reconfigure the microbiome to improve vaccine efficacy? As discussed in more detail later in this article, a more robust understanding of whether and what influence probiotics have on lentiviral susceptibility is necessary for informed vaccine design.

\section{Sex and Age Matter}

The push to reduce sexual disparity in health research has led to a wealth of interest in determining how the microbiome influences aspects of HIV infection in women. Although it is established that frequencies of specific taxa within the intestinal microbiome of male and female primates differ and may contribute to differential vaccine efficacy, it remains unclear whether and how the steady-state intestinal microbiome contributes to lentiviral disease in infected females [25, $30,72,74-76]$. However, several groups have begun to characterize the role of the vaginal microbiome in HIV acquisition [77, 78]. Initial studies which have aimed to develop the macaque model for studying acquisition aspects of HIV infection have revealed that there are striking dissimilarities between the human and macaque vaginal microbiomes. Whereas $50-80 \%$ of adult women harbor a Lactobacillusdominant vaginal microbiome, adult rhesus, pigtailed, and cynomolgous female macaques exhibit polymicrobial microbiomes [77, 79, 80•, 81-84]. Although it has been suggested that these differences make macaques an unsuitable model for female microbiome-associated studies, these differences may make the macaque an ideal model for assessing interventional regimens for women with polymicrobial microbiomes and as such, may be of great value to the HIV research field.

In human females, a Lactobacillus non-dominant vaginal microbiome is associated with a pro-inflammatory cervicovaginal milieu and a significantly increased risk of HIV acquisition [77]. It remains unclear what biological factors contribute to Lactobacillus dominance and whether the cervicovaginal microbiome can be durably modulated by therapeutic intervention [85]. Hallmaier-Wacker et al. found that menstruation is associated with a significant increase in alpha diversity and shift in beta-diversity among the rhesus vaginal microbiome [82]. Although vaginal community composition varies widely between individual macaques, Nugeyre et al. identified taxa that cycled with progesterone levels within individual cynomolgus macaques and similarly, Rhoades et al. observed that clinical markers of bacterial vaginosis differed significantly by menstrual status in rhesus macaques, as in women $[80 \bullet, 81,84,86]$. Menstrual-associated changes to the vaginal microbiome were not observed within the rhesus rectal microbiome, suggesting that menstrual hormones do not directly influence microbiomes at distal sites [80•]. Importantly, for most of the animals in these studies, a high degree of individuality was accompanied by a marked regularity to the vaginal microbiome over time suggesting an adaptation of the microbiome to its host. Efforts to colonize the female macaque microbiome with Lactobacillus by Lagenaur et al. have revealed that though robust through a single menstrual cycle, experimental colonization is not universally nor durably sustained [87-89]. Therapeutic colonization may require adjunct therapeutics such as the co-administration of keystone taxa, prebiotics or synbiotics $[90,91]$.

Mother-to-child transmission rates remain at $11 \%$, with transmission most likely to occur through consumption of biological material during birth or breastmilk in the absence of maternal ART $[92,93]$. There have been no studies thus far that have evaluated the relationship between the neonate microbiome and susceptibility to lentiviral infection. Like in humans, the microbiome of neonatal macaques is dramatically different from that of adults [94-97]. A detailed assessment of the rectal, oral, penile, and vaginal microbiomes of female and male infants, juveniles, and young, mid-aged, and older macaques by Janiak et al. demonstrated that infants have significantly differing measures of betadiversity across all tissues as compared to non-infants as well as higher measures of alpha diversity in the non-oral 
tissues [98•]. In non-infants, the microbiome of non-penile tissues did not significantly differ with age whereas the penile microbiome showed a great deal of plasticity.

These observations have two important implications in terms of HIV susceptibility. First - as juvenile macaques have the same microbiomes as adults - the juvenile and young adult microbiome composition is unlikely to uniquely contribute to HIV infection in young adult and adolescent humans. Indeed, Berard et al. observed that low-dose intravaginal SIV challenges did not reveal differential outcomes between juvenile and adult pigtailed macaques [99]. There were no observed differences by age in susceptibility to infection, vaginal immune cell subsets or inflammatory markers, or the vaginal microbiome. A second implication of neonatal microbiome plasticity is that there may exist a small window in neonates and infants in which to robustly elicit neutralizing, gp120-reactive antibodies, prior to B-cell imprinting by the microbiome $[69,70,100]$. To this end, Han et al. observed that vaccination of neonates with HIV-1 gp140 trimer induced more rapid gp120 neutralizing antibodies responses as compared to adults and overall higher levels of both gp41 and gp120 plasma antibodies [101]. Given the close relationship between diet, the maturing microbiome, and immune system development in human and macaque infants, it will be important to determine whether diet contributes to the development of natural and vaccine-elicited anti-SIV and anti-HIV humoral immunity [95, 102-104].

\section{Microbiome Therapies: Too Little or Too Much?}

Irrespective of the presence of a definable dysbiosis, extensive efforts are underway to alter the intestinal microbiome in progressive HIV and SIV infection. The administration of commensal taxa in the form of over-the-counter oral probiotics has gained favor as they are easy to administer, costeffective, and generally well-tolerated [105]. In NHPs, these studies have begun to lay the groundwork for human studies. In SIV-infected macaques, probiotic therapy has largely been administered in the context of ART as probiotic therapy alone does not prevent SIV infection nor CD4+T-cell losses [41, 47]. First demonstrated by Klatt et al., co-administration of probiotics and ART in chronically SIV-infected macaques led to improved CD4 + T-cell recovery and functionality, reduced colonic fibrosis, and increased expression of myeloid cell-related genes [41]. Looking to improve upon these results, Ortiz et al. further supplemented with IL-21 and observed a significant improvement in $\mathrm{T}_{\mathrm{H}} 17$ cell recovery [106]. It remains unclear whether these therapeutics broadly altered the intestinal microbiome.
Though promising, the oral ingestion of limited communities of bacteria in commercial probiotics is unlikely to have durable, pervasive effects on intestinal community structure and does not appear to be uniformly beneficial $[107,108]$. Fecal microbial transplantation (FMT) has risen as a more comprehensive, personalized approach to altering the intestinal microbiome that, while having caveats of its own, has been shown to durably improve microbial colonization and to preserve intestinal community structure [108-111]. Hensley-McBain et al. assessed the effect of a heterologous FMT on ART-treated, SIV-infected rhesus macaques and observed that although FMT was well-tolerated, treatment was not associated with significant immunological improvements [112]. While the colonic bacterial community composition quickly reverted to the pre-FMT community as assessed by beta-diversity, significant differences in minor taxa (uncategorized) remained evident.

With an observed role for the microbiome in influencing susceptibility to HIV and SIV infection, it follows that purposeful alteration of the intestinal microbiome may tune susceptibility [44••, 77]. Manuzak et al. recently assessed the influence of probiotic VSL\#3 on intestinal immune parameters in healthy male rhesus and pigtailed macaques [113]. After probiotic administration, the authors observed significant increases in colonic and lymph node myeloid cells, IgA + B-cells, increased LN TFH cells and intestinal innate lymphocyte type $3 \mathrm{~s}$, and decreased activation of colonic CD4 + T-cells. Similarly, Klatt et al. observed that co-administration of probiotic Visbiome with adjuvanted SIV Gag and HIV Env DNA/HIV gp140 trimer protein vaccination strategy, decreased target cell frequency, increased SIV gag-specific CD4 + and CD8 + T-cell responses, and increased $\operatorname{Ig} \mathrm{A}+\mathrm{LN}$ B-cells [114].

Though widely reported to have beneficial effects on gastrointestinal immunity, oral probiotic therapy in macaques has not been shown to extensively remodel the intestinal microbiome $[47,114]$ perhaps suggesting the potential for a finite number of taxa to influence susceptibility to SIV or HIV. In an effort to create a gastrointestinal pathogen-free (Campylobacter spp. and Shigella) macaque model, Bochart et al. treated rhesus macaques with enrofloxacin, paromomycin, and fenbendazole for 10 days and observed that absent extensive changes to the microbiome, this therapy led to improved systemic immunity, including reduced microbial translocation, reduced colonic granulocytes, and systemically reduced frequencies of activated CD4 + T-cells [115•]. Furthermore, this particular therapeutic was associated with a significantly decreased susceptibility to low-dose, intrarectal SIV challenge.

Where comprehensively analyzed, the probiotic and antibiotic therapies described above do not reveal an obvious reciprocal commensal:pathogen dichotomy suggesting that immunological benefits of these therapies may be associated 
with a recalibration of the metabolic networks shaped by the intestinal microbial ecosystem, more so than the presence or absence of specific taxa $[41,47,114,115 \bullet]$. Indeed, observational studies that have described an association between the macaque or human rectal microbiome and lentiviral acquisition did not identify the taxa utilized in the pre-therapeutic studies described here [30, 31, 44••]. It will be of interest to see which metabolic pathways are associated with protection from lentiviral acquisition and whether and how these pathways may be targeted by next-generation probiotics $[116,117]$.

\section{Odds and Ends}

Research into the contribution of the microbiome to lentiviral disease progression has largely been limited to the bacterial intestinal microbiome. Although necessary efforts to characterize the contribution of the microbiome to SIV disease progression at other anatomical sites have begun to emerge, the bacterial microbiome is not uniform throughout the gastrointestinal system [46, 47]. As first described by McKenna et al., there exist significant differences in bacterial beta-diversity of rhesus macaques between the upper and lower tract, colonic contents, and stool [25]. Described in further depth by Yasuda et al., whereas rhesus macaque stool and luminal contents are predominantly comprised of Firmicute families and Prevotellaceae, both the small and large intestinal mucosa are highly colonized by Proteobacteria [118]. Proteobacterial families differed by site, with the small intestine exhibiting an overrepresentation of Pasteurellaceae and the large intestine, Helicobacteriaceae. Despite these differences, the stool is largely reflective of both the colonic mucosa and luminal contents (both small and large intestine), displaying $97 \%$ congruence at the operational taxonomic unit level. Lee et al. additionally considered a comparison between the stomach and colon of Japanese macaques (Macaca fuscata yakui) and observed significantly differing beta-diversity [119]. Compared to the colon, the stomach was enriched for Verrucomicrobia, with reduced abundance of Firmicutes which translated largely into metabolic differences.

The microbiome is not limited to bacteria but rather, consists of a complex ecosystem including bacteria, viruses, and eukaryotic symbionts. In both humans and macaques, a lentiviral-associated perturbation of the virome has been described $[6,36,40,120]$. Whereas AIDS progression in humans is associated with expansions of Anelloviridae or Adenoviridae, progressive SIV infection is associated with expanded Adenoviridae alone [6, 36, 40, 120]. In SIVinfected macaques, Picornaviridae showed disease-state fluctuations - though overall expanded during chronic infection, Sapelovirus frequencies correlated with protection from infection and a loss of both Sapelovirus, and Enterovirus sequences accompanied AIDS progression. Although Adenoviridae, Adeno-associated virus, and Enterovirus sequences significantly correlated with the presence of gastrointestinal disease, causative effects of an altered virome remain unclear. In natural hosts of SIV infection, there are contradicting reports regarding the presence of an altered virome in chronic infection - whereas no expansion of the enteric microbiome was noted among captive, non-progressively SIV-infected African green monkeys, a significant expansion in disease-associated viruses was noted in wild gorillas [40, 121]. Efforts to understand whether and how the eukaryome contribute to HIV and SIV disease progression are even further unstudied. Although there are reports that fungal respiratory communities are disturbed in PLWH, it is unknown whether this may be a systemic phenomenon and mycobiome studies in the macaques have not advanced beyond surveys [122-126]. There are no reports thus far examining whether individual eukaryotes or eukaryotic networks associate with aspects of HIV and SIV disease progression. These areas of research remain underserved and may provide novel insight into mechanisms of chronic disease and AIDS progression.

\section{Conclusions}

Studies evaluating a contribution of the intestinal microbiome to SIV disease progression have not yet revealed commonalities in bacterial taxa that contribute to SIV acquisition, disease progression, or ART responsiveness. A lack of consensus may stem from experimental variation including cross-sectional analyses or reliance upon a phylogenetic assessment of the microbiome. Further studies are required to determine whether lentiviral-associated variations in the microbiome contribute to rather than reflect disease progression, and to evaluate the ability of microbiome-associated therapeutics to improve aspects of HIV acquisition or immunodeficiency.

Acknowledgements Funding was provided by the Division of Intramural Research/NIAID/NIH. The content of this publication does not necessarily reflect the views or policies of DHHS, nor does the mention of trade names, commercial products, or organizations imply endorsement by the US Government.

\section{Declarations}

Conflict of Interest The authors declare no competing interests.

Human and Animal Rights All reported studies/experiments with human or animal subjects performed by the authors have been previously published and complied with all applicable ethical standards (including the Helsinki declaration and its amendments, institutional/ national research committee standards, and international/national/institutional guidelines). 


\section{References}

Papers of particular interest, published recently, have been highlighted as:

- Of importance

$\bullet$ Of major importance

1. Allaire JM, Crowley SM, Law HT, Chang SY, Ko HJ, Vallance BA. The intestinal epithelium: central coordinator of mucosal immunity. Trends Immunol. 2018;39(9):677-96.

2. Lopez CA, Kingsbury DD, Velazquez EM, Baumler AJ. Collateral damage: microbiota-derived metabolites and immune function in the antibiotic era. Cell Host Microbe. 2014;16(2):156-63.

3. Dillon SM, Lee EJ, Kotter CV, Austin GL, Dong Z, Hecht DK, et al. An altered intestinal mucosal microbiome in HIV-1 infection is associated with mucosal and systemic immune activation and endotoxemia. Mucosal Immunol. 2014;7(4):983-94.

4. Lozupone CA, Li M, Campbell TB, Flores SC, Linderman D, Gebert MJ, et al. Alterations in the gut microbiota associated with HIV-1 infection. Cell Host Microbe. 2013;14(3):329-39.

5. Vujkovic-Cvijin I, Dunham RM, Iwai S, Maher MC, Albright $\mathrm{RG}$, Broadhurst MJ et al. Dysbiosis of the gut microbiota is associated with HIV disease progression and tryptophan catabolism. Sci Transl Med. 2013;5(193):193ra91.

6. Monaco CL, Gootenberg DB, Zhao G, Handley SA, Ghebremichael MS, Lim ES, et al. Altered virome and bacterial microbiome in human immunodeficiency virus-associated acquired immunodeficiency syndrome. Cell Host Microbe. 2016;19(3):311-22.

7. Sim JH, Mukerji SS, Russo SC, Lo J. Gastrointestinal dysfunction and HIV comorbidities. Curr HIV/AIDS Rep. 2021;18(1):57-62.

8. Ashuro AA, Lobie TA, Ye DQ, Leng RX, Li BZ, Pan HF, et al. Review on the alteration of gut microbiota: the role of HIV infection and old age. AIDS Res Hum Retroviruses. 2020;36(7):556-65.

9. Dillon SM, Wilson CC. What is the collective effect of aging and HIV on the gut microbiome? Curr Opin HIV AIDS. 2020;15(2):94-100.

10. Alzahrani J, Hussain T, Simar D, Palchaudhuri R, Abdel-Mohsen M, Crowe SM, et al. Inflammatory and immunometabolic consequences of gut dysfunction in HIV: parallels with IBD and implications for reservoir persistence and non-AIDS comorbidities. EBioMedicine. 2019;46:522-31.

11. Vujkovic-Cvijin I, Somsouk M. HIV and the gut microbiota: composition, consequences, and avenues for amelioration. Curr HIV/AIDS Rep. 2019;16(3):204-13.

12. Farcasanu M, Kwon DS. The influence of cervicovaginal microbiota on mucosal immunity and prophylaxis in the battle against HIV. Curr HIV/AIDS Rep. 2018;15(1):30-8.

13. Bandera A, De Benedetto I, Bozzi G, Gori A. Altered gut microbiome composition in HIV infection: causes, effects and potential intervention. Curr Opin HIV AIDS. 2018;13(1):73-80.

14. Desai SN, Landay AL. HIV and aging: role of the microbiome. Curr Opin HIV AIDS. 2018;13(1):22-7.

15. Brenchley JM, Price DA, Schacker TW, Asher TE, Silvestri $\mathrm{G}$, Rao S, et al. Microbial translocation is a cause of systemic immune activation in chronic HIV infection. Nat Med. 2006;12(12):1365-71.

16. Jiang W, Lederman MM, Hunt P, Sieg SF, Haley K, Rodriguez B, et al. Plasma levels of bacterial DNA correlate with immune activation and the magnitude of immune restoration in persons with antiretroviral-treated HIV infection. J Infect Dis. 2009;199(8):1177-85.
17. Merlini E, Bai F, Bellistri GM, Tincati C, d'Arminio Monforte A, Marchetti G. Evidence for polymicrobic flora translocating in peripheral blood of HIV-infected patients with poor immune response to antiretroviral therapy. PLoS One. 2011;6(4):e18580.

18. Nganou-Makamdop K, Talla A, Sharma AA, Darko S, Ransier $\mathrm{A}$, Laboune $\mathrm{F}$ et al. Translocated microbiome composition determines immunological outcome in treated HIV infection. Cell. 2021;184(15):3899-914 e16.

19. Ericsen AJ, Lauck M, Mohns MS, DiNapoli SR, Mutschler JP, Greene JM et al. Microbial translocation and inflammation occur in hyperacute immunodeficiency virus infection and compromise host control of virus replication. PLoS Pathog. 2016;12(12):e1006048.

20. Klase Z, Ortiz A, Deleage C, Mudd JC, Quinones M, Schwartzman E, et al. Dysbiotic bacteria translocate in progressive SIV infection. Mucosal Immunol. 2015;8(5):1009-20.

21. Rhesus Macaque Genome S, Analysis C, Gibbs RA, Rogers J, Katze MG, Bumgarner R et al. Evolutionary and biomedical insights from the rhesus macaque genome. Science. 2007;316(5822):222-34

22. Chimpanzee S, Analysis C. Initial sequence of the chimpanzee genome and comparison with the human genome. Nature. 2005;437(7055):69-87.

23. Policicchio BB, Pandrea I, Apetrei C. Animal models for HIV cure research. Front Immunol. 2016;7:12.

24. Chen Z, Yeoh YK, Hui M, Wong PY, Chan MCW, Ip M, et al. Diversity of macaque microbiota compared to the human counterparts. Sci Rep. 2018;8(1):15573.

25. McKenna P, Hoffmann C, Minkah N, Aye PP, Lackner A, Liu Z et al. The macaque gut microbiome in health, lentiviral infection, and chronic enterocolitis. PLoS Pathog. 2008;4(2):e20.

26. Dinh DM, Volpe GE, Duffalo C, Bhalchandra S, Tai AK, Kane $\mathrm{AV}$, et al. Intestinal microbiota, microbial translocation, and systemic inflammation in chronic HIV infection. J Infect Dis. 2015;211(1):19-27.

27. McHardy IH, Li X, Tong M, Ruegger P, Jacobs J, Borneman $\mathrm{J}$, et al. HIV infection is associated with compositional and functional shifts in the rectal mucosal microbiota. Microbiome. 2013;1(1):26.

28. Mutlu EA, Keshavarzian A, Losurdo J, Swanson G, Siewe B, Forsyth $\mathrm{C}$ et al. A compositional look at the human gastrointestinal microbiome and immune activation parameters in HIV infected subjects. PLoS Pathog. 2014;10(2):e1003829.

29. Vazquez-Castellanos JF, Serrano-Villar S, Latorre A, Artacho A, Ferrus ML, Madrid N, et al. Altered metabolism of gut microbiota contributes to chronic immune activation in HIV-infected individuals. Mucosal Immunol. 2015;8(4):760-72.

30. Armstrong AJS, Shaffer M, Nusbacher NM, Griesmer C, Fiorillo S, Schneider JM, et al. An exploration of Prevotella-rich microbiomes in HIV and men who have sex with men. Microbiome. 2018;6(1):198

31. Noguera-Julian M, Rocafort M, Guillen Y, Rivera J, Casadella M, Nowak P, et al. Gut microbiota linked to sexual preference and HIV infection. EBioMedicine. 2016;5:135-46.

32. Kelley CF, Kraft CS, de Man TJ, Duphare C, Lee HW, Yang J, et al. The rectal mucosa and condomless receptive anal intercourse in HIV-negative MSM: implications for HIV transmission and prevention. Mucosal Immunol. 2017;10(4):996-1007.

33. Vujkovic-Cvijin I, Sortino O, Verheij E, Sklar J, Wit FW, Kootstra NA, et al. HIV-associated gut dysbiosis is independent of sexual practice and correlates with noncommunicable diseases. Nat Commun. 2020;11(1):2448.

34. Allers K, Stahl-Hennig C, Fiedler T, Wibberg D, Hofmann J, Kunkel D, et al. The colonic mucosa-associated microbiome in SIV infection: shift towards Bacteroidetes coincides with 
mucosal CD4(+) T cell depletion and enterocyte damage. Sci Rep. 2020;10(1):10887.

35. Glavan TW, Gaulke CA, Santos Rocha C, Sankaran-Walters S, Hirao LA, Raffatellu M, et al. Gut immune dysfunction through impaired innate pattern recognition receptor expression and gut microbiota dysbiosis in chronic SIV infection. Mucosal Immunol. 2016;9(3):677-88.

36. Handley SA, Desai C, Zhao G, Droit L, Monaco CL, Schroeder $\mathrm{AC}$, et al. SIV infection-mediated changes in gastrointestinal bacterial microbiome and virome are associated with immunodeficiency and prevented by vaccination. Cell Host Microbe. 2016;19(3):323-35.

37. Siddiqui S, Bao D, Doyle-Meyers L, Dufour J, Wu Y, Liu $\mathrm{YZ}$, et al. Alterations of the gut bacterial microbiota in rhesus macaques with SIV infection and on short- or long-term antiretroviral therapy. Sci Rep. 2020;10(1):19056.

38. Vujkovic-Cvijin I, Swainson LA, Chu SN, Ortiz AM, Santee CA, Petriello A, et al. Gut-resident Lactobacillus abundance associates with IDO1 inhibition and Th17 dynamics in SIV-infected macaques. Cell Rep. 2015;13(8):1589-97.

39. Blum FC, Hardy BL, Bishop-Lilly KA, Frey KG, Hamilton T, Whitney JB, et al. Microbial dysbiosis during simian immunodeficiency virus infection is partially reverted with combination anti-retroviral therapy. Sci Rep. 2020;10(1):6387.

40. Handley SA, Thackray LB, Zhao G, Presti R, Miller AD, Droit $\mathrm{L}$, et al. Pathogenic simian immunodeficiency virus infection is associated with expansion of the enteric virome. Cell. 2012;151(2):253-66.

41. Klatt NR, Canary LA, Sun X, Vinton CL, Funderburg NT, Morcock DR et al. Probiotic/prebiotic supplementation of antiretrovirals improves gastrointestinal immunity in SIV-infected macaques. J Clin Invest. 2013;123(2):903-7.

42.•• Ortiz AM, Flynn JK, DiNapoli SR, Vujkovic-Cvijin I, Starke $\mathrm{CE}$, Lai SH et al. Experimental microbial dysbiosis does not promote disease progression in SIV-infected macaques. Nat Med. 2018;24(9):1313-6. This is the first paper to experimentally evaluate a contribution of dysbiosis to SIV disease progression. Vancomycin use in macaques recapitulated the dysbiosis commonly described in PLWH and demonstrated that intestinal bacterial dysbiosis does not necessarily accelerate disease progression.

43. Ivanov II, Frutos Rde L, Manel N, Yoshinaga K, Rifkin DB, Sartor RB, et al. Specific microbiota direct the differentiation of IL-17-producing T-helper cells in the mucosa of the small intestine. Cell Host Microbe. 2008;4(4):337-49.

44.• Sui Y, Dzutsev A, Venzon D, Frey B, Thovarai V, Trinchieri $\mathrm{G}$ et al. Influence of gut microbiome on mucosal immune activation and SHIV viral transmission in naive macaques. Mucosal Immunol. 2018;11(4):1219-29. Rhesus macaques originating from different sources and harboring distinct microbiomes were found to have differing susceptibilities to rectal SHIV infection. CD4+ T-cells frequencies and rectal inflammation correlated with susceptibility and intestinal Prevotella:Bacteroides.

45. Vujkovic-Cvijin I, Sklar J, Jiang L, Natarajan L, Knight R, Belkaid Y. Host variables confound gut microbiota studies of human disease. Nature. 2020;587(7834):448-54.

46. Morris A, Paulson JN, Talukder H, Tipton L, Kling H, Cui L, et al. Longitudinal analysis of the lung microbiota of cynomolgous macaques during long-term SHIV infection. Microbiome. 2016;4(1):38.

47. Jones R, Kroll K, Broedlow C, Schifanella L, Smith S, Hueber B, et al. Probiotic supplementation reduces inflammatory profiles but does not prevent oral immune perturbations during SIV infection. Sci Rep. 2021;11(1):14507.
48. Beck JM, Schloss PD, Venkataraman A, Twigg H 3rd, Jablonski KA, Bushman FD, et al. Multicenter comparison of lung and oral microbiomes of HIV-infected and HIV-uninfected individuals. Am J Respir Crit Care Med. 2015;192(11):1335-44.

49. Lozupone C, Cota-Gomez A, Palmer BE, Linderman DJ, Charlson ES, Sodergren E, et al. Widespread colonization of the lung by Tropheryma whipplei in HIV infection. Am J Respir Crit Care Med. 2013;187(10):1110-7.

50. Twigg HL 3rd, Knox KS, Zhou J, Crothers KA, Nelson DE, Toh E, et al. Effect of advanced HIV infection on the respiratory microbiome. Am J Respir Crit Care Med. 2016;194(2):226-35.

51. Ortiz AM, Flynn JK, DiNapoli SR, Sortino O, Vujkovic-Cvijin I, Belkaid Y et al. Antiretroviral therapy administration in healthy rhesus macaques is associated with transient shifts in intestinal bacterial diversity and modest immunological perturbations. J Virol. 2019;93(18).

52. Perler BK, Reinhart EM, Montgomery M, Maynard M, Shapiro JM, Belenky P, et al. Evaluation of the microbiome in men taking pre-exposure prophylaxis for HIV prevention. AIDS Behav. 2021;25(7):2005-13.

53. Fulcher JA, Li F, Cook RR, Zabih S, Louie A, Okochi $\mathrm{H}$ et al. Rectal microbiome alterations associated with oral human immunodeficiency virus pre-exposure prophylaxis. Open Forum Infect Dis. 2019;6(11):ofz463.

54. Dube MP, Park SY, Ross H, Love TMT, Morris SR, Lee HY. Daily HIV pre-exposure prophylaxis (PrEP) with tenofovir disoproxil fumarate-emtricitabine reduced Streptococcus and increased Erysipelotrichaceae in rectal microbiota. Sci Rep. 2018;8(1):15212.

55. Patel S PC, Bernice F. Vancomycin. Treasure Island (FL): StatPearls Publishing.

56. Collini PJ, Kuijper E, Dockrell DH. Clostridium difficile infection in patients with HIV/AIDS. Curr HIV/AIDS Rep. 2013;10(3):273-82.

57. Bisson GP, Zetola N, Collman RG. Persistent high mortality in advanced HIV/TB despite appropriate antiretroviral and antitubercular therapy: an emerging challenge. Curr HIV/AIDS Rep. 2015;12(1):107-16.

58. Department of Health and Human Services. Panel on Guidelines for the Prevention and Treatment of Opportunistic Infections in Adults and Adolescents with HIV. Guidelines for the prevention and treatment of opportunistic infections in HIV-infected adults and adolescents: recommendations from the Centers for Disease Control and Prevention, the National Institutes of Health, and the HIV Medicine Association of the Infectious Diseases Society of America. [database on the Internet]. Available from: https:// clinicalinfo.hiv.gov/sites/default/files/inline-files/adult_oi.pdf. Accessed:August 21, 2021

59. Guillen Y, Noguera-Julian M, Rivera J, Casadella M, Zevin AS, Rocafort M, et al. Low nadir CD4+ T-cell counts predict gut dysbiosis in HIV-1 infection. Mucosal Immunol. 2019;12(1):232-46.

60. Jasinska AJ, Dong TS, Lagishetty V, Katzka W, Jacobs JP, Schmitt CA, et al. Shifts in microbial diversity, composition, and functionality in the gut and genital microbiome during a natural SIV infection in vervet monkeys. Microbiome. 2020;8(1):154.

61. Moeller AH, Shilts M, Li Y, Rudicell RS, Lonsdorf EV, Pusey AE, et al. SIV-induced instability of the chimpanzee gut microbiome. Cell Host Microbe. 2013;14(3):340-5.

62. Barbian HJ, Li Y, Ramirez M, Klase Z, Lipende I, Mjungu D et al. Destabilization of the gut microbiome marks the end-stage of simian immunodeficiency virus infection in wild chimpanzees. Am J Primatol. 2018;80(1).

63. Zevin AS, Xie IY, Birse K, Arnold K, Romas L, Westmacott $\mathrm{G}$ et al. Microbiome composition and function drives 
wound-healing impairment in the female genital tract. PLoS Pathog. 2016;12(9):e1005889.

64. Tipton L, Muller CL, Kurtz ZD, Huang L, Kleerup E, Morris A, et al. Fungi stabilize connectivity in the lung and skin microbial ecosystems. Microbiome. 2018;6(1):12.

65. Velazquez EM, Nguyen H, Heasley KT, Saechao CH, Gil LM, Rogers AWL, et al. Endogenous Enterobacteriaceae underlie variation in susceptibility to Salmonella infection. Nat Microbiol. 2019;4(6):1057-64.

66. de Jong SE, Olin A, Pulendran B. The impact of the microbiome on immunity to vaccination in humans. Cell Host Microbe. 2020;28(2):169-79.

67. Tomaras GD, Yates NL, Liu P, Qin L, Fouda GG, Chavez LL, et al. Initial B-cell responses to transmitted human immunodeficiency virus type 1: virion-binding immunoglobulin M (IgM) and IgG antibodies followed by plasma anti-gp41 antibodies with ineffective control of initial viremia. J Virol. 2008;82(24):12449-63.

68. Williams WB, Liao HX, Moody MA, Kepler TB, Alam SM, Gao $\mathrm{F}$ et al. Diversion of HIV-1 vaccine-induced immunity by gp41-microbiota cross-reactive antibodies. Science. 2015;349(6249):aab1253.

69. Trama AM, Moody MA, Alam SM, Jaeger FH, Lockwood B, Parks R, et al. HIV-1 envelope gp41 antibodies can originate from terminal ileum B cells that share cross-reactivity with commensal bacteria. Cell Host Microbe. 2014;16(2):215-26.

70. Han Q, Williams WB, Saunders KO, Seaton KE, Wiehe KJ, Vandergrift $\mathrm{N}$ et al. HIV DNA-adenovirus multiclade envelope vaccine induces gp41 antibody immunodominance in rhesus macaques. J Virol. 2017;91(21).

71. Sui Y, Lewis GK, Wang Y, Berckmueller K, Frey B, Dzutsev A, et al. Mucosal vaccine efficacy against intrarectal SHIV is independent of anti-Env antibody response. J Clin Invest. 2019;129(3):1314-28.

72. Musich T, Thovarai V, Venzon DJ, Mohanram V, Tuero I, MillerNovak LK et al. A prime/boost vaccine regimen alters the rectal microbiome and impacts immune responses and viremia control post-simian immunodeficiency virus infection in male and female rhesus macaques. J Virol. 2020;94(24).

73. Elizaldi SR, Verma A, Walter KA, Rolston M, Dinasarapu AR, Durbin-Johnson BP et al. Rectal microbiome composition correlates with humoral immunity to HIV-1 in vaccinated rhesus macaques. mSphere. 2019;4(6)

74. Haro C, Rangel-Zuniga OA, Alcala-Diaz JF, Gomez-Delgado F, Perez-Martinez P, Delgado-Lista J et al. Intestinal microbiota is influenced by gender and body mass index. PLoS One. 2016;11(5):e0154090.

75. Dominianni C, Sinha R, Goedert JJ, Pei Z, Yang L, Hayes RB et al. Sex, body mass index, and dietary fiber intake influence the human gut microbiome. PLoS One. 2015;10(4):e0124599.

76. Scully EP. Sex Differences in HIV Infection. Curr HIV/AIDS Rep. 2018;15(2):136-46.

77. Gosmann C, Anahtar MN, Handley SA, Farcasanu M, AbuAli G, Bowman BA, et al. Lactobacillus-deficient cervicovaginal bacterial communities are associated with increased HIV acquisition in young South African women. Immunity. 2017;46(1):29-37.

78. Klatt NR, Cheu R, Birse K, Zevin AS, Perner M, Noel-Romas $\mathrm{L}$, et al. Vaginal bacteria modify HIV tenofovir microbicide efficacy in African women. Science. 2017;356(6341):938-45.

79. Ravel J, Gajer P, Abdo Z, Schneider GM, Koenig SS, McCulle SL, et al. Vaginal microbiome of reproductive-age women. Proc Natl Acad Sci U S A. 2011;108(Suppl 1):4680-7.

80.• Rhoades NS, Hendrickson SM, Gerken DR, Martinez K, Slayden $\mathrm{OD}$, Slifka MK et al. Longitudinal profiling of the macaque vaginal microbiome reveals similarities to diverse human vaginal communities. mSystems. 2021;6(2). This publication comprehensively and longitudinally documents the diversity and instability of the macaque vaginal microbiome and demonstrates its functional similarity to that of women with recurring bacterial vaginosis.

81. Spear GT, Gilbert D, Sikaroodi M, Doyle L, Green L, Gillevet $\mathrm{PM}$, et al. Identification of rhesus macaque genital microbiota by $16 \mathrm{~S}$ pyrosequencing shows similarities to human bacterial vaginosis: implications for use as an animal model for HIV vaginal infection. AIDS Res Hum Retroviruses. 2010;26(2):193-200.

82. Hallmaier-Wacker LK, Luert S, Roos C, Knauf S. Lactation and menstruation shift the vaginal microbiota in captive rhesus monkeys to be more similar to the male urethral microbiota. Sci Rep. 2019;9(1):17399.

83. Spear GT, Kersh E, Guenthner P, Vishwanathan SA, Gilbert D, Zariffard MR, et al. Longitudinal assessment of pigtailed macaque lower genital tract microbiota by pyrosequencing reveals dissimilarity to the genital microbiota of healthy humans. AIDS Res Hum Retroviruses. 2012;28(10):1244-9.

84. Nugeyre MT, Tchitchek N, Adapen C, Cannou C, Contreras V, Benjelloun F, et al. Dynamics of vaginal and rectal microbiota over several menstrual cycles in female cynomolgus macaques. Front Cell Infect Microbiol. 2019;9:188.

85. Petrova MI, van den Broek M, Balzarini J, Vanderleyden J, Lebeer S. Vaginal microbiota and its role in HIV transmission and infection. FEMS Microbiol Rev. 2013;37(5):762-92.

86. Gajer P, Brotman RM, Bai G, Sakamoto J, Schutte UM, Zhong $\mathrm{X}$ et al. Temporal dynamics of the human vaginal microbiota. Sci Transl Med. 2012;4(132):132ra52.

87. Lagenaur LA, Swedek I, Lee PP, Parks TP. Robust vaginal colonization of macaques with a novel vaginally disintegrating tablet containing a live biotherapeutic product to prevent HIV infection in women. PLoS One. 2015;10(4):e0122730.

88. Yu RR, Cheng AT, Lagenaur LA, Huang W, Weiss DE, Treece $\mathrm{J}$, et al. A Chinese rhesus macaque (Macaca mulatta) model for vaginal Lactobacillus colonization and live microbicide development. J Med Primatol. 2009;38(2):125-36.

89. Daggett GJ Jr, Zhao C, Connor-Stroud F, Oviedo-Moreno P, Moon $\mathrm{H}$, Cho MW, et al. Comparison of the vaginal environment in rhesus and cynomolgus macaques pre- and post-lactobacillus colonization. J Med Primatol. 2017;46(5):232-8.

90. Banerjee S, Schlaeppi K, van der Heijden MGA. Keystone taxa as drivers of microbiome structure and functioning. Nat Rev Microbiol. 2018;16(9):567-76.

91. Sanders ME, Merenstein DJ, Reid G, Gibson GR, Rastall RA. Probiotics and prebiotics in intestinal health and disease: from biology to the clinic. Nat Rev Gastroenterol Hepatol. 2019;16(10):605-16.

92. UNAIDS. Key HIV epidemiology indicators for children and adolescents aged 0-19, 2000-2020 [database on the Internet]. Available from: https://data.unicef.org/topic/hivaids/global-regio nal-trends/. Accessed:July 29, 2021

93. Lumaca A, Galli L, de Martino M, Chiappini E. Paediatric HIV-1 infection: updated strategies of prevention mother-tochild transmission. J Chemother. 2018;30(4):193-202.

94. Stewart CJ, Ajami NJ, O'Brien JL, Hutchinson DS, Smith DP, Wong MC, et al. Temporal development of the gut microbiome in early childhood from the TEDDY study. Nature. 2018;562(7728):583-8.

95. Backhed F, Roswall J, Peng Y, Feng Q, Jia H, KovatchevaDatchary $\mathrm{P}$, et al. Dynamics and stabilization of the human gut microbiome during the first year of life. Cell Host Microbe. 2015;17(5):690-703.

96. Lim ES, Zhou Y, Zhao G, Bauer IK, Droit L, Ndao IM, et al. Early life dynamics of the human gut virome and bacterial microbiome in infants. Nat Med. 2015;21(10):1228-34. 
97. Yatsunenko T, Rey FE, Manary MJ, Trehan I, Dominguez-Bello MG, Contreras M, et al. Human gut microbiome viewed across age and geography. Nature. 2012;486(7402):222-7.

98. Janiak MC, Montague MJ, Villamil CI, Stock MK, Trujillo AE, DePasquale AN et al. Age and sex-associated variation in the multi-site microbiome of an entire social group of free-ranging rhesus macaques. Microbiome. 2021;9(1):68. A detailed comparison of rectal, oral, penile, and vaginal microbiomes of macaques across age and sex demonstrating that once established, these microbiomes are largely conserved with the exception of a dynamic penile microbiome.

99. Berard AR, Miller C, Arainga M, Broedlow CA, Noel-Romas L, Schifanella L, et al. Simian immunodeficiency virus susceptibility, immunology, and microbiome in the female genital tract of adolescent versus adult pigtail macaques. AIDS Res Hum Retroviruses. 2021;37(7):510-22.

100. Wesemann DR, Portuguese AJ, Meyers RM, Gallagher MP, Cluff-Jones K, Magee JM, et al. Microbial colonization influences early B-lineage development in the gut lamina propria. Nature. 2013;501(7465):112-5.

101. Han Q, Bradley T, Williams WB, Cain DW, Montefiori DC, Saunders KO et al. Neonatal rhesus macaques have distinct immune cell transcriptional profiles following HIV envelope immunization. Cell Rep. 2020;30(5):1553-69 e6.

102. Baumann-Dudenhoeffer AM, D'Souza AW, Tarr PI, Warner BB, Dantas G. Infant diet and maternal gestational weight gain predict early metabolic maturation of gut microbiomes. Nat Med. 2018;24(12):1822-9.

103. Ardeshir A, Narayan NR, Mendez-Lagares G, Lu D, Rauch M, Huang Y et al. Breast-fed and bottle-fed infant rhesus macaques develop distinct gut microbiotas and immune systems. Sci Transl Med. 2014;6(252):252ra120.

104. Narayan NR, Mendez-Lagares G, Ardeshir A, Lu D, Van Rompay KK, Hartigan-O'Connor DJ. Persistent effects of early infant diet and associated microbiota on the juvenile immune system. Gut Microbes. 2015;6(4):284-9.

105. Suez J, Zmora N, Segal E, Elinav E. The pros, cons, and many unknowns of probiotics. Nat Med. 2019;25(5):716-29.

106. Ortiz AM, Klase ZA, DiNapoli SR, Vujkovic-Cvijin I, Carmack K, Perkins MR, et al. IL-21 and probiotic therapy improve Th17 frequencies, microbial translocation, and microbiome in ARV-treated. SIV-infected macaques Mucosal Immunol. 2016;9(2):458-67.

107. Zmora N, Zilberman-Schapira G, Suez J, Mor U, Dori-Bachash $\mathrm{M}$, Bashiardes $\mathrm{S}$ et al. Personalized gut mucosal colonization resistance to empiric probiotics is associated with unique host and microbiome features. Cell. 2018;174(6):1388-405 e21.

108. Suez J, Zmora N, Zilberman-Schapira G, Mor U, Dori-Bachash $\mathrm{M}$, Bashiardes S et al. Post-antibiotic gut mucosal microbiome reconstitution is impaired by probiotics and improved by autologous FMT. Cell. 2018;174(6):1406-23 e16.

109. Ridaura VK, Faith JJ, Rey FE, Cheng J, Duncan AE, Kau AL, et al. Gut microbiota from twins discordant for obesity modulate metabolism in mice. Science. 2013;341(6150):1241214.

110. Chehoud C, Dryga A, Hwang Y, Nagy-Szakal D, Hollister EB, Luna RA et al. Transfer of viral communities between human individuals during fecal microbiota transplantation. mBio. 2016;7(2):e00322.

111. DeFilipp Z, Bloom PP, Torres Soto M, Mansour MK, Sater MRA, Huntley MH et al. Drug-resistant E. coli bacteremia transmitted by fecal microbiota transplant. N Engl J Med. 2019;381(21):2043-50.

112. Hensley-McBain T, Zevin AS, Manuzak J, Smith E, Gile J, Miller C, et al. Effects of fecal microbial transplantation on microbiome and immunity in simian immunodeficiency virusinfected macaques. J Virol. 2016;90(10):4981-9.
113. Manuzak JA, Hensley-McBain T, Zevin AS, Miller C, Cubas R, Agricola B, et al. Enhancement of microbiota in healthy macaques results in beneficial modulation of mucosal and systemic immune function. J Immunol. 2016;196(5):2401-9.

114. Klatt NR, Broedlow C, Osborn JM, Gustin AT, Dross S, O'Connor MA, et al. Effects of persistent modulation of intestinal microbiota on SIV/HIV vaccination in rhesus macaques. NPJ Vaccines. 2021;6(1):34.

115.•• Bochart RM, Busman-Sahay K, Bondoc S, Morrow DW, Ortiz AM, Fennessey CM et al. Mitigation of endemic GI-tract pathogen-mediated inflammation through development of multimodal treatment regimen and its impact on SIV acquisition in rhesus macaques. PLoS Pathog. 2021;17(5):e1009565. Utilizing a therapeutic antibiotic regimen, this is the first generation of gastrointestinal pathogen-free macaques. Without widespread disruption to the microbiome, these macaques had improved intestinal epithelial barriers, reduced mucosal and systemic inflammation, and reduced susceptibility to rectal SIV challenge.

116. El Hage R, Hernandez-Sanabria E, Van de Wiele T. Emerging trends in "Smart Probiotics": functional consideration for the development of novel health and industrial applications. Front Microbiol. 2017;8:1889.

117. Scott BM, Gutierrez-Vazquez C, Sanmarco LM, da Silva Pereira JA, Li Z, Plasencia A, et al. Self-tunable engineered yeast probiotics for the treatment of inflammatory bowel disease. Nat Med. 2021;27(7):1212-22.

118. Yasuda K, Oh K, Ren B, Tickle TL, Franzosa EA, Wachtman LM, et al. Biogeography of the intestinal mucosal and lumenal microbiome in the rhesus macaque. Cell Host Microbe. 2015; 17(3):385-91.

119. Lee W, Hayakawa T, Kurihara Y, Hanzawa M, Sawada A, Kaneko A et al. Stomach and colonic microbiome of wild Japanese macaques. Am J Primatol. 2021;83(5):e23242.

120. Li L, Deng X, Linsuwanon P, Bangsberg D, Bwana MB, Hunt $\mathrm{P}$, et al. AIDS alters the commensal plasma virome. J Virol. 2013;87(19):10912-5.

121. D'Arc M, Furtado C, Siqueira JD, Seuanez HN, Ayouba A, Peeters M, et al. Assessment of the gorilla gut virome in association with natural simian immunodeficiency virus infection. Retrovirology. 2018;15(1):19.

122. Cui L, Lucht L, Tipton L, Rogers MB, Fitch A, Kessinger C, et al. Topographic diversity of the respiratory tract mycobiome and alteration in HIV and lung disease. Am J Respir Crit Care Med. 2015;191(8):932-42.

123. Mukherjee PK, Chandra J, Retuerto M, Tatsuoka C, Ghannoum MA, McComsey GA. Dysbiosis in the oral bacterial and fungal microbiome of HIV-infected subjects is associated with clinical and immunologic variables of HIV infection. PLoS One. 2018;13(7):e0200285.

124. Sawaswong V, Chanchaem P, Khamwut A, Praianantathavorn K, Kemthong T, Malaivijitnond $\mathrm{S}$ et al. Oral-fecal mycobiome in wild and captive cynomolgus macaques (Macaca fascicularis). Fungal Genet Biol. 2020;144:103468.

125. Sun B, Xia Y, Garber PA, Amato KR, Gomez A, Xu X et al. Captivity is associated with gut mycobiome composition in Tibetan macaques (Macaca thibetana). Front Microbiol. 2021;12:665853.

126. Sun B, Gu Z, Wang X, Huffman MA, Garber PA, Sheeran LK et al. Season, age, and sex affect the fecal mycobiota of freeranging Tibetan macaques (Macaca thibetana). Am J Primatol. 2018;80(7):e22880.

Publisher's Note Springer Nature remains neutral with regard to jurisdictional claims in published maps and institutional affiliations. 